\title{
Adaptation of Organizational Justice in Sport Scale into Turkish Language: Validity and Reliability Study
}

\author{
Ayfer Sayin ${ }^{1}$, Mustafa Yaşar Şahin ${ }^{1}$ \\ ${ }^{1}$ Gazi University, Turkey \\ Correspondence: Ayfer Sayin, Gazi University, Turkey
}

Received: December 14, 2016

Accepted: January 3, 2017 Online Published: January 20, 2017

doi:10.11114/jets.v5i2.2071

URL: http://dx.doi.org/10.11114/jets.v5i2.2071

\begin{abstract}
The present study aimed to provide a Turkish adaptation of the Organizational Justice in Sport Scale and perform reliability and validity studies. Answers provided by 260 participants who work as football, male basketball and female basketball coaches in National Collegiate Athletic Association (NCAA) were analysed using the original scale that comprised 17 items and three dimensions rated on a Likert-type 7-point scale. Subsequently, the opinions of 210 coaches were obtained. Confirmatory factor analysis conducted at the end of the study determined that the standardized regression coefficients vary between 0.45 and 0.92 . Model-fit indexes showed that Turkish version of the scale had high construct validity. It was found that the corrected item-total correlation varied between 0.589 and 0.846 . Further, it was determined that there were medium-/high-level positive correlations between sub-dimensions. Cronbach's alpha reliability coefficient was calculated as 0.957 . The authors concluded that the Turkish version of the Organizational Justice in Sport Scale was a valid, reliable and convenient measurement tool for determining the level of Organizational justice among the coaches.
\end{abstract}

Keywords: organizational justice, sports coach, scale adaptation

\section{Introduction}

In contemporary times, particularly extreme and destructive competitive conditions as a result of the free market economy have rapidly frayed organizations that cannot keep up with the necessities of time and even obligated these organizations to withdraw from the field. The current organizational structure has transformed into a more flexible structure prioritizing horizontal positioning, increasing communication between employees by creating control mechanisms and increasing the importance of the intra-organization network structure (Akyel, 2014).

Academic studies have largely reflected this tendency. This process expedited the creation of a new 'concept stack' which is adopted by assessing the pragmatic values currently discussed in the management discipline to a greater extent. The phenomenon of 'organizational justice' expressing fair distribution of achievements acquired as a result of intra-Organizational hierarchy and human relationships has also been a subject of this new concept stack (Özen, 2002).

It has always been acknowledged that life is just for individuals living in the society. From this viewpoint, individuals develop a comparison and judgement for life elements such as wages, reward and punishment and manager behaviour in their workplaces, which constitute one of the most important parts in the lives of people. This leads them to create some thoughts and behavioural patterns towards workplaces (Irak, 2004). In this context, many social scientists for a long time have recognized the importance of justice as a fundamental problem required for organizations to fulfil their functions effectively and ensure personal satisfaction of their employees (Greenberg, 1987).

Although various disciplines have accorded different meanings, the concept of justice in general implies respecting human rights and providing equal rights. In this context, justice provides the basis for building interpersonal relationships within a community and relations with other communities (Özen, 2002).

Social sciences study the phenomenon of justice in detail and investigate it from many different perspectives. It is observed that the organizational theories developed in recent years have focused on interaction between individuals and problems arising from that interaction. In this context, it is observed that the 'social justice' concept has also been adapted to organizations and the concept of 'Organizational justice', expressing fair distribution of achievements arising as a result of intra-organizations relations, has been developed (İşbaşı Özen, 2001). 
The studies on Organizational justice that have become the focus of interest for almost everyone from different disciplines are based on Adam's Equity Theory introduced in 1965. Adams based his theory on the assumption that an organization's employees would compare the achievements arising from their own efforts with the achievements of employees working in other organizations (Demirel \& Seçkin, 2001). As a result of this comparison, an employee develops attitudes towards the organization, his managers and his job. Underlying these attitudes are justice perceptions developed by an individual regarding general practice and the organization's systems (Özdevecioğlu, 2003). In this regard, organizational justice can be defined as perceptions of employees about the rightness of the organization's conduct (Campbell \& Finch, 2004). While Moorman (1991) defined organizational justice as a term describing justice directly related to workspaces, Özkalp \& Kırel (2004) defined justice perceived in all social and economic mutual exchanges as a concept incorporating the relation of an individual with his/her superior, colleagues and organization's structures in a social system. According to Folger \& Cronpanzano (1998), organizational justice refers to procedures used while distributing the achievements and taking distribution decisions and the developed rules and norms related to interpersonal dynamics (citied by Polat \& Kazak, 2014).

\section{Dimensions of Organizational Justice}

In literature, different researchers have identified organizational justice as distributive, transactional and interactional justice. In particular, Greenberg (1987) examined this concept in three dimensions as justice in acquisitions (distributive justice), processes (procedural justice) and inter-personal relations (interactional justice).

According to this researcher, the following factors have propelled these three dimensions to the forefront and have had a profound effect on organizational justice (Greenberg, 1987):

- Distributive Justice: Organizational outcomes affect the organization positively or negatively depending on the perception of justness in the distribution of justice.

- Procedural Justice: Organizational practices affect the perception of justice through the processes used by the organization.

- Interactional Justice: Organizational practices affect the perception of justice through behaviours exhibited and statements made by the authorities within an organization.

The following paragraphs examine the dimensions of organizational justice in detail:

Distributive justice: Distributive justice implies the allocation of proportional shares by pre-defined sources to individuals based on defined standards, functional rules and provisions. The individuals may perceive their outcomes (i.e. income, premiums, promotion and social rights) as fair or unfair. They may compare their acquisitions with others. As a result, they may feel that they have been treated unfairly. These thoughts affect their attitudes and behaviours, and individuals may change according to their attitudes. An essential characteristic of distributive justice is that individuals assume that they have a just share of distributed resources (Özdevecioğlu, 2003). The processes determining the distribution judgements undoubtedly affect the perception of justice related to distribution. In fact, in some cases, the processes determining these outputs may be more important than the output itself. Thus, the concept of procedural justice has emerged focusing on these processes and procedures (Greenberg, 1987).

Procedural justice: Procedural justice refers to the degree of justness in the methods, procedures and policies used in the determination or measurement of elements such as wages, promotion, financial opportunities, working conditions and performance evaluation. For instance, the justness in the distribution of performance rewards constitutes the subject of distributive justice, whereas the justness in the methods used in determining the same performance rewards constitutes the subject of procedural justice. While procedural justice has a general dimension and broader sense (in the organizational dimension), distributive justice is related to individual outputs such as wage. In terms of determining distributive justice, the importance of procedural justice is crucial for organizational management and success (Greenberg, 1987).

Interactional justice: Interactional justice concentrates on the social part of Organizational justice and emphasizes investments in inter-personal relations and outcomes from these relations. Due to the fact that economic factors are not the only sufficient condition for securing justice between employees and managers, researchers have focused on socio-psychological aspects of organizational justice (Yeniçeri, Demirel \& Seçkin, 2009). In this study, the Organizational Justice in Sport Scale also has three dimensions: distributive, procedural and interactional justice.

\section{Significance of This Study}

In organizations, managers started being attentive towards the human factor for increasing productivity and efficiency. Organizational behaviour experts who investigate the human factor have begun citing concepts such as organizational justice. The level of perception of Organizational justice, particularly in areas of sports comprising activities based on 
individuals, is affecting the output of human resources positively or negatively.

A gradual increase in the economic and political significance of sports in addition to its social impact reveals the truth that sports institutions and organizations must be managed using the most efficient and effective methods. From this viewpoint, sports managers such as organization manager, director, trainer, technical director, referee, and physical education teacher, who reflect positive images regarding justice and exhibit characteristics of high emotional intelligence, may play a significant role in the success of the organizational structure.

Although coaches play a vital role in sports activities, scientific studies on this subject are rather limited on both international and national scales. This fact is negatively affecting the development of effective practices of coaches, actualising appropriate styles pertinent to the necessities of the players' time, performance and development. It becomes obvious that the Organizational justice concept must be scrutinized with respect to sports. Considering the fact that Organizational justice scales generally practiced in the Organizational field do not include the practices of the coaches, it can be stated that the scale planned for adaptation into Turkish might satisfy the deficiency in this respect. The adapted scale would enable the assessment of the coaches' level of justice and direct future studies.

\section{Method}

\subsection{Research Model}

The present study aimed to provide the Turkish adaptation of the Organizational Justice in Sport Scale developed by Kim (2009) and perform reliability and validity studies of the adapted scale. Accordingly, the present study was designed as a descriptive study and aimed to describe, compare, classify, analyse and interpret the characteristics of individuals, groups, institutions, methods or materials (Cohen, Manion \& Morrison, 2005).

\subsection{Study Group}

In the scope of the present reliability and validity study, Organizational Justice in Sport Scale was administered to 210 coaches who participated in the spring courses prepared for coaches in Turkey. Of these coaches, $78.6 \%(\mathrm{n}=165)$ were males and 21.4\% $(\mathrm{n}=45)$ were females. Of these coaches, 32.9\% $(\mathrm{n}=69)$ were in the $21-30$ years age group, $34.8 \%(\mathrm{n}$ $=73)$ were in the $31-40$ years age group, $22.9 \%(\mathrm{n}=48)$ were in the $41-50$ years age group and $9.5 \%(\mathrm{n}=20)$ were in the 51 years or older age group. In total, $61.9 \%$ of the coaches were married and $38.1 \%(\mathrm{n}=80)$ were single. When the educational level of the coaches was evaluated, it was found that $29.5 \%(\mathrm{n}=62)$ were high school graduates, $62.9 \%(\mathrm{n}$ $=132)$ had an undergraduate degree and $7.6 \%(\mathrm{n}=16)$ had a postgraduate degree. The level of experience was $0-5$ years in $31.4 \%(\mathrm{n}=66), 6-10$ years in $21.0 \%(\mathrm{n}=44), 11-15$ years in $24.8 \%(\mathrm{n}=52)$ and more than 16 years in $22.9 \%$ $(\mathrm{n}=48)$ of the coaches. Of the coaches who participated in the reliability and validity study of the scale, $30.5 \%(\mathrm{n}=64)$ were coaching stars, $39.0 \%(\mathrm{n}=82)$ were coaching youths and $30.5 \%(\mathrm{n}=64)$ were coaching adults. The participants were from 19 different branches, and 26.2\% $(\mathrm{n}=55)$ had Level 1, 42.9\% $(\mathrm{n}=90)$ had Level 2, 20.0\% $(\mathrm{n}=42)$ had Level 3 and $11.0 \%(n=23)$ had Level 4 Certificates in coaching.

\subsection{Data Collection Tool}

The original version of the Organizational Justice in Sport Scale comprises 17 items designed to assess the level of justice of players. The items are rated on a Likert-type 7-point scale wherein 1 indicates 'Strongly Disagree' and 7 indicates 'Strongly Agree'. The scale comprises three dimensions and all items of the scale indicate a positive characteristic. Information related to the scale's dimensions is shown in Table 1.

Table 1. Dimensions of the scale and item numbers

\begin{tabular}{lcl}
\hline Dimensions of the scale & $\mathrm{n}$ & Sample Items \\
\hline Distributive Justice & 4 & $\begin{array}{l}\text { Team budget is consistent with the efforts made. } \\
\text { Team budget is adequate for what we would like to achieve. }\end{array}$ \\
Procedural Justice & 7 & $\begin{array}{l}\text { I feel free to express my opinions related to resource allocation in the club. } \\
\text { I think I might be effective in resource allocation in the club. }\end{array}$ \\
Interactional Justice & $6 \begin{array}{l}\text { I have good relations with my club managers. } \\
\text { My manager shares with me how to do source allocation. }\end{array}$
\end{tabular}

Examination of Table 1 reveals that there are three dimensions in the Organizational Justice in Sport Scale; the procedural justice dimension $(n=7)$ contains the highest number of items and the distributive justice dimension $(n=4)$ contains the lowest number of items.

In the development process of the Organizational Justice in Sport Scale, the scale was administered to 260 participants who worked as football, men's basketball, and female's basketball coaches in NCAA. Confirmatory factor analysis (CFA) was performed using the original scale and the participants' answers. It demonstrated that all the items in the respective dimension had a significant $t$ value. It was found that the factor loadings ranged from 0.776 to 0.841 in the distributive justice dimension, from 0.454 to 0.827 in the procedural justice dimension and from 0.699 to 0.856 in the 
interactional justice dimension. Model-data fit indexes used previously were calculated after determining that all the items were significantly explanatory in their respective dimension. Fit indices $(\mathrm{X} 2 / \mathrm{df}=1.969$; RMSEA $=0.061, \mathrm{CFI}=$ 0.847 ) showed that model-data fit was achieved. In other words, the scale comprising 17 items and three dimensions was confirmed. Cronbach's alpha coefficient was calculated for determining the reliability of the coaches' answers. Cronbach's alpha coefficient was 0.888 for the items related to the distributive justice dimension, 0.839 for the items related to the procedural justice dimension and 0.904 for the items related to the interactional justice dimension (Kim, 2009).

The original validated Organization Justice in Sport Scale was successfully adapted to the Turkish language.

\subsection{Data Analysis}

The authors have resorted to expert opinions for determining content validity of the scale during the Turkish adaptation of the Organizational Justice in Sport Scale. A CFA was conducted to determine the construct validity. The Cronbach's alpha and item-total correlation coefficients were calculated for determining the reliability of the answers. In addition, Pearson's correlation coefficient was calculated for determining the relationships between the scale's dimensions.

The assumptions were examined before proceeding to data analysis. The sample size $(n=210)$ was sufficient for a 17 -item scale, and there were no missing data in the dataset. It was found that the skewness and kurtosis coefficients of the items varied between -1 and +1 and the $z$ values varied between -3 and +3 . The analysis was performed after examining normality and outliers.

\section{Results}

First, the scale's items and instructions were translated into the Turkish language while adapting the Organizational Justice in Sport Scale in Turkish. The documents were then re-translated into Turkish to perform a consistency check between the translated documents, and initial corrections were made. The opinions of one English language expert and one Turkish measurement and assessment expert were obtained, and the translation documents were finalized. Then, seven lecturers in the Faculty of Sports Science evaluated the scale's items for their conformity with the Turkish culture and the relevance of these items to their respective dimension. In accordance with opinions of experts, 'resource allocation' was replaced with 'budget' and the term 'athletics administrators' was replaced with 'sports managers'. All items were pertinent to the respective dimension. After finalizing the translations, two sports coaches were required to answer scale items verbally, and it was found that there was no incomprehensible item in the scale and no item that the participants would abstain from responding. Then, the scale was administered to 210 coaches, and the calculations were based on their answers.

\subsection{Results of CFA}

CFA was conducted for evaluating the extent to which the data obtained from the coaches were consistent with the factor structure of the scale's original version. It focused on examining the extent to which the edited or predetermined structure confirmed with the collected data. Thus, CFA refers to the testing of certain variables using predetermined factors and models (Schumacker and Lomax 2004). Further, it is used to test the confirmation of a factorial structure predetermined by the investigator (Çerezci 2010). Numerous fit indices are used to assess the model's validity using CFA. Among these, the Chi-square Compliance Test (Chi-Square Goodness, $\chi 2$ ) and the Comparative Fit Index (Comparative Fit Index, CFI) (Sumerian 2000) are the most commonly used testing methods.

Figure 1 shows the path diagram created after the CFA was conducted for the 17-item Organizational Justice in Sport Scale was administered to the coaches. 


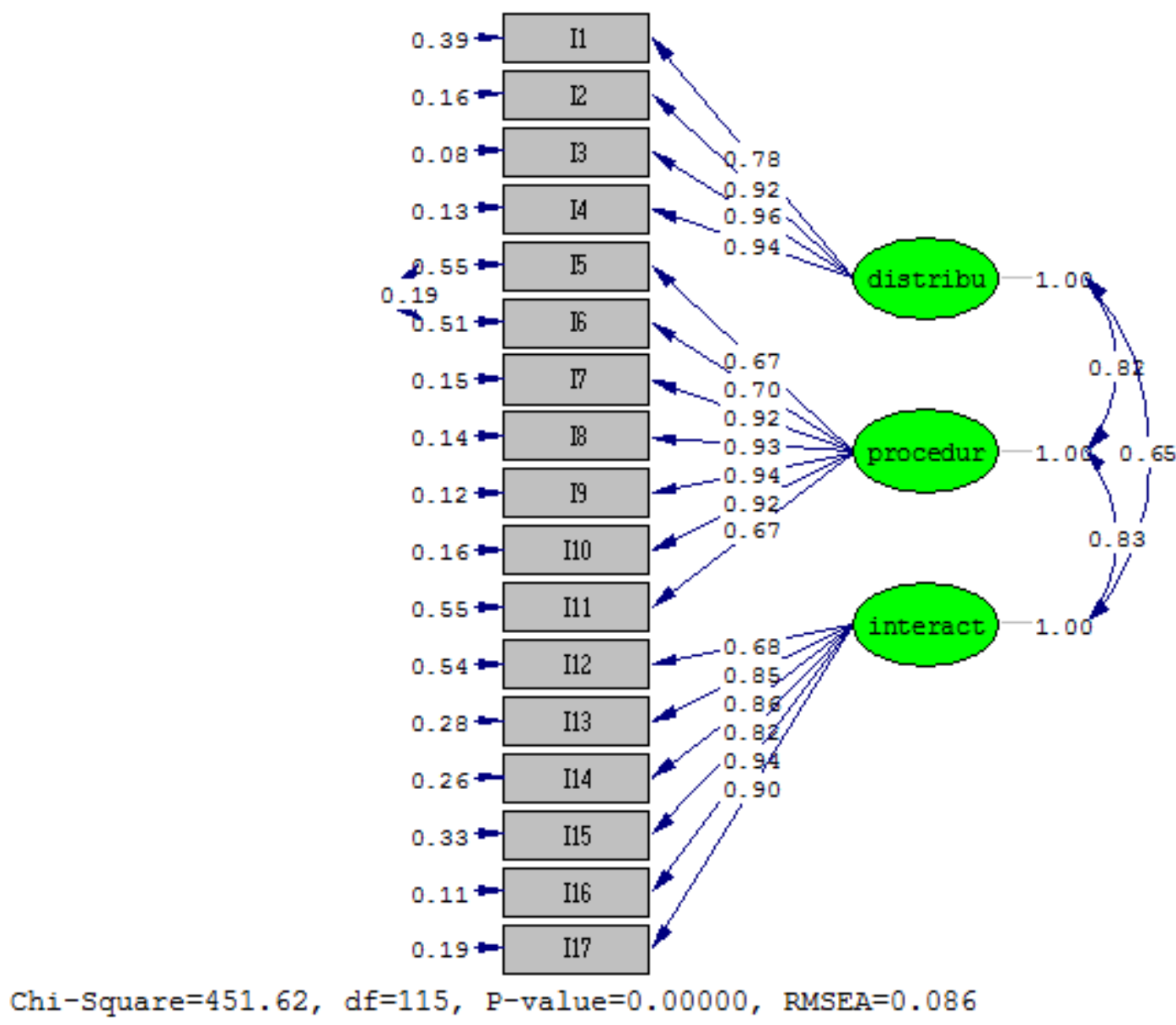

Figure 1. The path diagram (standardised solution) created by confirmatory factor analysis of organizational justice in sport scale

When the path diagram in Figure 1 was examined, it was observed that all the items had significant $t$ values in their respective dimensions. In other words, all the items could significantly explain their respective dimensions. Table 2 shows regression and $t$ values of the items.

Table 2. Regression and $t$ values of Organizational justice in sport scale calculated by CFA

\begin{tabular}{|c|c|c|c|}
\hline Dimensions & Items & Regression Values $\left(\mathrm{R}^{2}\right)$ & $\mathrm{t}$ values \\
\hline \multirow{4}{*}{ Distributive Justice } & $\mathrm{I} 1$ & 0.61 & 13.75 \\
\hline & $\mathrm{I} 2$ & 0.84 & 17.64 \\
\hline & $\mathrm{I} 3$ & 0.92 & 19.14 \\
\hline & $\mathrm{I} 4$ & 0.87 & 18.31 \\
\hline \multirow{7}{*}{ Procedural Justice } & $\mathrm{I} 5$ & 0.45 & 11.12 \\
\hline & I6 & 0.49 & 11.86 \\
\hline & $\mathrm{I} 7$ & 0.85 & 17.82 \\
\hline & I8 & 0.86 & 18.10 \\
\hline & I9 & 0.88 & 18.52 \\
\hline & $\mathrm{I} 10$ & 0.84 & 17.72 \\
\hline & $\mathrm{I} 11$ & 0.45 & 11.20 \\
\hline \multirow{6}{*}{ Interactional Justice } & $\mathrm{I} 12$ & 0.46 & 11.30 \\
\hline & I13 & 0.72 & 15.47 \\
\hline & I14 & 0.74 & 15.80 \\
\hline & $\mathrm{I} 15$ & 0.67 & 14.70 \\
\hline & I16 & 0.89 & 18.53 \\
\hline & $\mathrm{I} 17$ & 0.81 & 17.08 \\
\hline
\end{tabular}

When the data in Table 2 were examined, it was observed that the regression coefficients varied between 0.45 and 0.92 in the Turkish version of the Organizational Justice in Sport Scale. Regression coefficients for the distributive justice dimension, which is the scale's first dimension, varied between 0.61 and 0.92 . It was found that the third item of the 
distributive justice dimension was this dimension's most explanatory item $\left(\mathrm{R}^{2}=0.92\right)$ and the first item was this dimension's least explanatory item $\left(\mathrm{R}^{2}=0.61\right)$. It was determined that the regression coefficients of the procedural justice dimension varied between 0.45 and 0.88 . The most explanatory item in the procedural justice dimension was the ninth item $\left(R^{2}=0.88\right)$, whereas the eleventh and fifth items were the least explanatory items $\left(R^{2}=0.45\right)$. Regression coefficients for the scale's last dimension, i.e. the interactional justice dimension, varied between 0.46 and 0.89 . The most explanatory item in the interactional justice dimension was the sixteenth item $\left(R^{2}=0.89\right)$, whereas the twelfth item was the least explanatory item $\left(R^{2}=0.46\right)$.

During the model's calculation process, model-data fit values were calculated after confirming that all the items met the assumption of linearity and had significant explanatory values. The results are shown in Table 3.

Table 3. Model-fit values of Organizational justice in sport scale calculated by CFA

\begin{tabular}{lllllll}
\hline $\mathbf{X}^{2}$ & df & $\mathbf{X}^{2} / \mathbf{d f}$ & RMSEA & CFI & IFI & NFI \\
\hline 451.62 & 115 & 3.93 & 0.086 & 0.97 & 0.97 & 0.96 \\
\hline
\end{tabular}

When the values in Table 3 were examined, the $\mathrm{X}^{2} / \mathrm{df}$ value was less than 4 , the RMSEA value was slightly higher than 0.80 and the CFI, IFI and NFI values were higher than 0.95 . In this respect, 17 items and the three-dimensional structure in the original structure of the scale were checked with the answers obtained from Turkish coaches. In other words, model-data fit was achieved.

\subsection{Analysis of the Items and Calculation of Reliability}

After verifying the construct validity in accordance with the answers obtained from the coaches in the scope of the present research, item-total correlation coefficients were examined. The results are presented Table 4.

Examination of Table 4 revealed that the item-total correlation coefficient varied between 0.605 and 0.767 in the distributive justice dimension, between 0.648 and 0.846 in the procedural justice dimension and between 0.589 and 0.794 in the interactional justice dimension. In the interpretation of item-total correlation, items with a coefficient of 0.30 and higher differentiated the individuals more comprehensively (Büyüköztürk, 2008). Thus, it can be asserted that the items in the Organizational Justice in Sport Scale are highly distinctive.

The Cronbach's alpha coefficient was calculated to determine the reliability of the answers provided by the coaches. It was found to be 0.923 for the items of the distributive justice dimension, 0.924 for the items of the procedural justice dimension and 0.918 for the items of the interactional justice dimension. The reliability coefficient calculated for all items of the scale was 0.957 . In other words, coaches' answers to scale items were regarded as reliable.

Table 4. Corrected item-total correlation coefficients of Organizational justice in sport scale

\begin{tabular}{lll}
\hline \multirow{3}{*}{ Dimensions } & Items & $\begin{array}{l}\text { Corrected } \\
\text { correlation }\end{array}$ \\
\hline \multirow{3}{*}{ Distributive Justice } & $\mathrm{I} 1$ & .605 \\
\cline { 2 - 3 } Procedural Justice & $\mathrm{I} 2$ & .722 \\
\cline { 2 - 3 } & $\mathrm{I} 3$ & .766 \\
\cline { 2 - 3 } & $\mathrm{I} 4$ & .767 \\
\cline { 2 - 3 } & $\mathrm{I} 5$ & .690 \\
\cline { 2 - 3 } I6 & .677 \\
\cline { 2 - 3 } Interactional Justice & $\mathrm{I} 8$ & .822 \\
\cline { 2 - 3 } & $\mathrm{I} 9$ & .809 \\
\cline { 2 - 3 } & $\mathrm{I} 10$ & .846 \\
\cline { 2 - 3 } & $\mathrm{I} 11$ & .846 \\
\cline { 2 - 3 } & $\mathrm{I} 12$ & .648 \\
\cline { 2 - 3 } & $\mathrm{I} 13$ & .696 \\
\cline { 2 - 3 } & $\mathrm{I} 14$ & .794 \\
\cline { 2 - 3 } & $\mathrm{I} 15$ & .785 \\
\cline { 2 - 3 } & $\mathrm{I} 16$ & .782 \\
\cline { 2 - 3 } & $\mathrm{I} 17$ & \\
\hline
\end{tabular}

\subsection{Calculation of the Correlation between Dimensions}

Pearson's correlation coefficient was calculated for determining the relations between the distributive, procedural and interactional justice dimensions. The results are shown in Table 5. 
Table 5. Relationship between the dimensions of the Organizational justice in sport scale

\begin{tabular}{|c|c|c|c|c|c|}
\hline $\begin{array}{l}\text { Dimensions } \\
\text { Justice }\end{array}$ & Values & $\begin{array}{l}\text { Organizational } \\
\text { Justice }\end{array}$ & $\begin{array}{l}\text { Distributive } \\
\text { Justice }\end{array}$ & Procedural Justice & Interactional Justice \\
\hline \multirow{3}{*}{$\begin{array}{l}\text { Organizational } \\
\text { Justice }\end{array}$} & $\mathrm{r}$ & 1 & 0.835 & 0.957 & 0.892 \\
\hline & $\mathrm{p}$ & . & 0.000 & 0.000 & 0.000 \\
\hline & $\mathrm{N}$ & 210 & 210 & 210 & 210 \\
\hline \multirow[t]{3}{*}{ Distributive Justice } & $\mathrm{r}$ & 0.835 & 1 & 0.739 & 0.580 \\
\hline & $\mathrm{p}$ & 0.000 & & 0.000 & 0.000 \\
\hline & $\mathrm{N}$ & 210 & 210 & 210 & 210 \\
\hline \multirow[t]{3}{*}{ Procedural Justice } & $\mathrm{r}$ & 0.957 & 0.739 & 1 & 0.796 \\
\hline & $\mathrm{p}$ & 0.000 & 0.000 & . & 0.000 \\
\hline & $\mathrm{N}$ & 210 & 210 & 210 & 210 \\
\hline \multirow[t]{3}{*}{ Interactional Justice } & $\mathrm{r}$ & 0.892 & 0.580 & 0.796 & 1 \\
\hline & $\mathrm{p}$ & 0.000 & 0.000 & 0.000 & . \\
\hline & $\mathrm{N}$ & 210 & 210 & 210 & 210 \\
\hline
\end{tabular}

Examination of Table 5 showed that there was a high-grade positive correlation between the distributive justice and procedural justice dimensions of the scale $(r=0.739 ; \mathrm{p}<0.05)$. There was also a moderately positive correlation between the distributive justice and interactional justice dimensions of the scale $(r=0.580 ; p<0.05)$. There was a high-grade positive correlation between the interactional justice and procedural justice dimensions of the scale $(\mathrm{r}=$ $0.796 ; \mathrm{p}<0.05)$.

As shown in Table 5, there were high-grade correlations between Organizational justice and distributive justice dimensions $(r=0.835 ; \mathrm{p}<0.05)$ and procedural justice $(\mathrm{r}=0.957 ; \mathrm{p}<0.05)$ and interactional justice dimensions $(\mathrm{r}=$ $0.892 ; \mathrm{p}<0.05)$ of the scale.

\section{Discussion}

In the present study the Organizational Justice in Sports Scale prepared by Kim (2009) was adapted to the Turkish language, performed validity and reliability studies were performed. Similar to the original scale's validity study, the scale was adapted using the coaches and players' managers. The opinions of 210 coaches were obtained in this regard. During the adaptation process, the scale's instructions and items were translated into the Turkish language and then translated back into English. After completing the process of translation, the first expert group evaluated the items and the second expert group finalized the documents. Subsequently, the scale was administered to the coaches.

First, CFA was conducted with the answers of the coaches. This analysis confirmed that all the items had significant $t$ values in their respective dimensions. Regression coefficients of 17 items ranged between 0.45 and 0.92 . Tabachnick \& Fidell (2005) suggested that a regression coefficient of 0.45 and higher would be highly explanatory. The items in the Organizational Justice in Sport Scale were highly explanatory in their respective dimensions. In Kim's (2009) original study, factorial validity values ranged between 0.776 and 0.841 for the distributive justice dimension, between 0.454 and 0.827 for the procedural justice dimension and between 0.699 and 0.856 for the interactional justice dimension. The adaptation data were consistent with the results of the original validity study.

In the calculation of the model-data fit, the $\mathrm{X}^{2} / \mathrm{df}$ value was 3.93, RMSEA value was 0.086 , CFR value was 0.97, IFI value was 0.97 and NF value was 0.96 . Schermelleh-Engel, Moosbrugger \& Müller (2003) have suggested that a $\mathrm{X}^{2} / \mathrm{df}$ value less than 4, RMSEA value less than 0.80, and CFI, IFI and NFI values higher than 0.95 would provide a good model-data fit. Accordingly, the model has been verified. Data fit indices were at an acceptable level in the developmental phase of the original scale $\left(\mathrm{X}^{2} / \mathrm{df}=1.969 ; \mathrm{RMSEA}=0.061, \mathrm{CFI}=0.847\right)(\mathrm{Kim}, 2009)$.

Total-item correlation coefficient of the items in the scale ranged between 0.589 and 0.846 . The total-item correlation is a measure reflecting the relationship between the score obtained from the test items and the total score of the test. It can be argued that an item-correlation coefficient of 0.30 and higher would enable better differentiation of the measured characteristic of an individual better (Büyüköztürk, 2008). Accordingly, the items in the Organization Justice in Sport Scale had a good discriminative power.

Cronbach's alpha coefficient was 0.923 for the items of the distributive justice dimension, 0.924 for the items of the procedural justice dimension and 0.918 for the items of the interactional justice dimension. The reliability coefficient calculated for the whole scale was 0.957. Kalayc1 (2009) suggested that an alpha coefficient of 0.80 and higher would indicate a highly reliable scale. The responses provided by the coaches were found to be highly reliable. In the original validity study conducted by Kim (2009), Cronbach's alpha coefficient was 0.888 for the items related to the distributive justice dimension, 0.839 for the items related to the procedural justice dimension, and 0.904 for the items related to the interactional justice dimension. The adapted scale achieved higher reliability coefficients.

There were high-grade correlations between Organizational justice and distributive justice dimensions $(r=0.835 ; \mathrm{p}<$ 
$0.05)$ and procedural justice $(r=0.957 ; \mathrm{p}<0.05)$ and interactional justice dimensions $(\mathrm{r}=0.892 ; \mathrm{p}<0.05)$. The presence of a higher correlation between the dimensions of the Organizational Justice in Sports Scale suggests that the highest scores can be achieved using this scale.

The authors concluded that the Turkish version of the Organizational Justice in Sport Scale was a valid, reliable and convenient measurement tool for determining the level of Organizational justice among the coaches.

\section{References}

Akyel, Y. (2014). Organizational justice and relationship of organizational trust. Doctor of Philosophy Degree, Gazi University, Graduate School of Health Sciences. Ankara

Büyüköztürk, Ş. (2008). Data analysis handbook for social sciences. Statistics, research design SPSS applications and comments. Ankara: PegemA Publishing.

Campbell, L., \& Finch, E. (2004). Customer satisfaction and organizational justice. Facilities 22(7/8), 178-189. https://doi.org/10.1108/02632770410547543

Cohen, L., Manion, L., \& Morrison, K. (2005). Research methods in education. London: RoutledgeFalmer.

Demirel, Y., \& Seçkin, Z. (2001). The impact of organizational justice on knowledge sharing: Research on drug industry employees. Bilig, 56, 99- 119.

Greenberg, J.A. (1987). Taxonomy of organizational justicetheories. The Academy of Management Review, 12(1), 9-22.

Irak, D. U. (2004). Organizational Justice: Appearance, Theoretical Approaches and Current State. Organizational Justice: Appearance, Theoretical Approaches and Current State, 7(13), 20-36.

İşbaş1, Ö. J. (2001). The effect of organizational justice perception and organizational commitment on burnout: An investigation on Turkish public sector. BILIG , 57, 175-200.

Kalayc1, S.., (2009). SPSS applied multivariate statistical techniques. Ankara: Asil Publication.

Kim (2009). The impact of met-expectation of organizational justice on attitudinal and behavioral outcomes of intercollegiate athletics coaches. Doctor of Philosophy Degree, The University of Tennessee, Knoxville.

Moorman, R. H. (1991). Relationship between organizational justice and organizational citizenship behaviors: Do fairness perception influence employee citizenship?. Journal of Applied Psychology, 76(6), 845-855. https://doi.org/10.1037/0021-9010.76.6.845

Özdevecioğlu, M. (2003). A research to determine the effects of perceived organizational justice on individual aggressive behaviors. Erciyes University Journal of Economics and Administrative Sciences, 21, 77-96.

Özen, J. (2002). The development of justice theories and types of organizational justice. Archives of Philosophy of Law and Sociology, 5, 107-117.

Özkalp, E., \& Kırel, Ç. (2004). Organizational behavior. Eskişehir: Anadolu University Publications.

Polat, S., \& Kazak, E. (2014). The Correlation between School Principals' Favoritist Behaviors and Attitudes and Teachers' Perception of Organizational Justice. Educational Administration: Theory and Practice, 20(1), 71-92.

Schermelleh-Engel, K., Moosbrugger, H., \& Müller, H. (2003). Evaluating the fit of structural equation models: Tests of significance and descriptive goodness-of-fit measures. Methods of Psychological Research Online, 8(2), 23-74.

Tabachnick, B. G., \& Fidell, L. S. (2007). Using multivariate statistics. Boston: Allyn and Bacon.

Yeniçeri, Ö., Demirel, Y., \& Seçkin, Z. (2009). The Relationship between Organizational Justice and Emotional Burnout: A Research Over Manufacturing Industry Employees. KMU Journal of Social and Economic Research, 11(16), 83-99.

\section{Copyrights}

Copyright for this article is retained by the author(s), with first publication rights granted to the journal.

This is an open-access article distributed under the terms and conditions of the Creative Commons Attribution license which permits unrestricted use, distribution, and reproduction in any medium, provided the original work is properly cited. 